\title{
VHDL Realization of Hybrid Control Strategy for a Nonlinear System
}

\author{
John Kalloor \\ P.G. Student, Dept. of E \& I Engg. \\ Annamalai University, \\ Tamil Nadu, India
}

\author{
S. Meyyappan \\ Ass. Prof. in Dept. of E \& I Engg. \\ Annamalai University, \\ Tamil Nadu, India
}

\begin{abstract}
The Process Industries are automated to keeping in tune with the changing requirements. It creates the need of a well defined philosophy to cater to the extent of sophistication. The Scheme projects a mechanism to adapt to the evolving scenario and orient a strategy to accomplish the desired objective. A conical tank system is chosen and a methodology designed to eclipse the specified liquid level in it through appropriate hydraulic arrangements. It augurs the need of a well defined control algorithm to charter a corrective action and seeks the role of a state of the art processor to implement the procedure. The self tuning Fuzzy-PI control algorithm is coded using VHDL and is evaluated through Modlsim based simulation to verify its practical viability.
\end{abstract}

\section{Keywords}

Conical tank, Self tuning Fuzzy-PI, VHDL, Z-N.

\section{INTRODUCTION}

The control of liquid level in tank and flow between tanks is a basic problem in the process industries. It requires liquids to be pumped, stored in tanks, and there after transferred to another tank. Many times the fluids are processed by chemical or mixing treatment in the tanks, but always the level of fluid in the tanks must be controlled, and the flow between tanks regulated. A host of industries where liquid level and flow control are essential include petro-chemical, paper making and water treatment industries.

In fact, the lives of human beings are governed by level and flow control systems. For example, the medical physiology involves many fluid bio-control systems. Bio-systems in human body are there to control the rate that blood flow around human body. Other bio-systems control the pressure and level of moisture and chemicals in the human body. Thus it is essential for control systems engineers to understand how tank systems work and how the level control problem is solved. The tank level control system is the part and parcel of process industries and P, PI, and PID controllers are being used in the process industries as cost effective approaches to improve about improving its performance and efficiency without using other approaches. Fuzzy logic has rapidly become one of the most successful tools of today's technology in the development of sophisticated control systems [4,5]. A fuzzy PI controller takes the conventional PI controller as the foundation which uses the fuzzy reasoning and variable universe of discourse to regulate the PID parameters [12].

Suppressing the influence of external disturbances on a process is the most common objective at a controller. Thus it is necessary to introduce a control mechanism that will make the proper changes on the process to cancel the negative impact that such disturbance may have on the desired operation of the plant [2].The rapid technological development of digital computers during the past couple of decades, coupled with significant relation of their cost, has had very profound effect on process control application [11] VHDL has constructs that enable the user to express the concurrent or sequential behavior at a digital system with or without timing. It also allows the user to model the system as an interconnection of components. Test waveforms can also be generated using the same constructs. Moreover all the constructs may be combined together to provide a comprehensive description of the system in a single model [1]. A modeling approach for describing fuzzy controllers using statecharts and VHDL has been proposed in [7,14]. The statecharts description of the rule base is translated into VHDL and integrated with the hand-coded VHDL code realizing fuzzification and defuzzification components. An attempt has been made to present the history of classical PID controllers and their enhancements using fuzzy logic theory [10]. FPGA have become an ideal solution for the realization of digital control systems, previously dominated by the general purpose microprocessor systems [6]. The run-time reconfigurable nature of FPGA may be used to detect and cope up with the possible occurrences of errors at different stages of the process $[3,13]$. The FPGA based controllers offer advantages such as high speed, complex functionality and low power consumption $[8,9]$.

Control of liquid level in process vessels often involves two important and conflicting considerations. The changes in flow rates out of the vessel is desired to be as a smooth as possible so as not to upset the downstream process and it is preferred that the level does not deviate too for the desired normal operating point. It is in this perspective that it is proposed to employ a VLSI based strategy to maintain the level in the tank at the specified set point. The algorithm is designed to handle both servo and regulatory disturbances, which is developed through VHDL to perform the function of a controller and ensure the desired performance.

\section{PROCESS DESCRIPTION AND MODELLING}

The schematic of the chosen level process is shown in fig. 1. The system consists of a conical shaped process tank, a storage tank, a pump, pneumatic control valve, rotameter, an I/P converter, differential pressure transmitter, I/V and V/I converter ,by pass valve and VMAT interfacing card with data converters.

Mathematical representation of the process is part and parcel in control applications. Normally a process may be well defined by its transfer function model. Such transfer function can be expressed in terms of continuous variables. The process under study is a conical tank shown in fig. 2. 


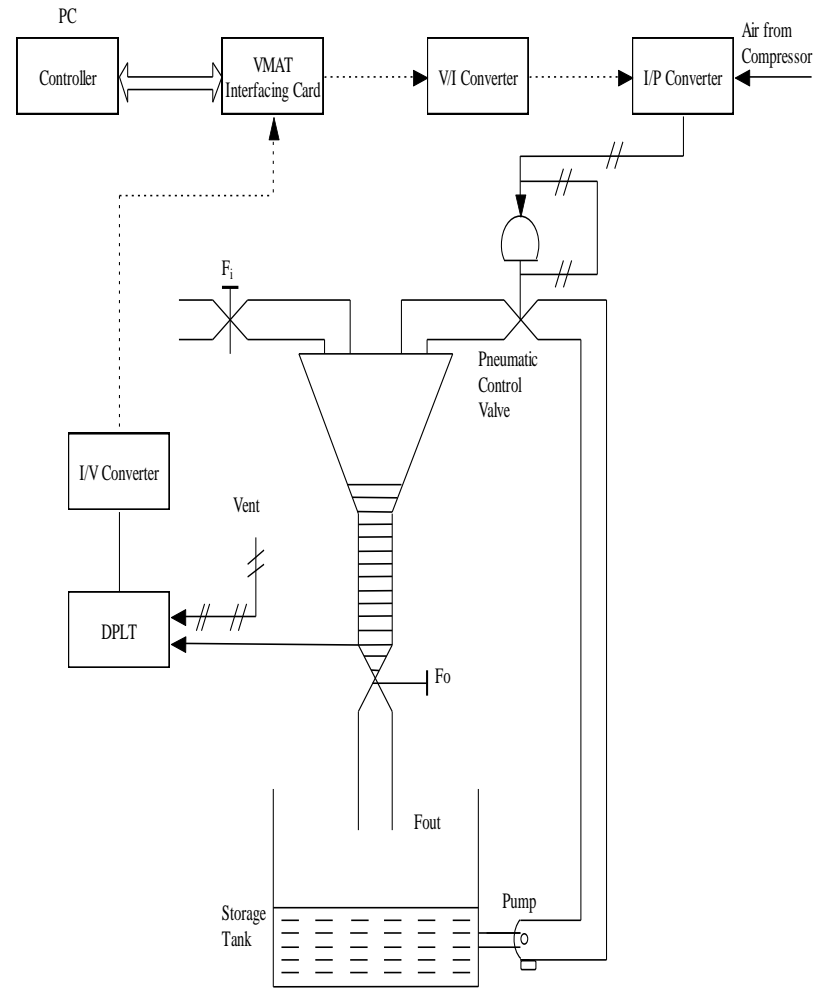

Fig. 1 Schematic of the under study level Process

\section{MATHEMATICAL MODEL OF THE CONICAL TANK LEVEL PROCESS}

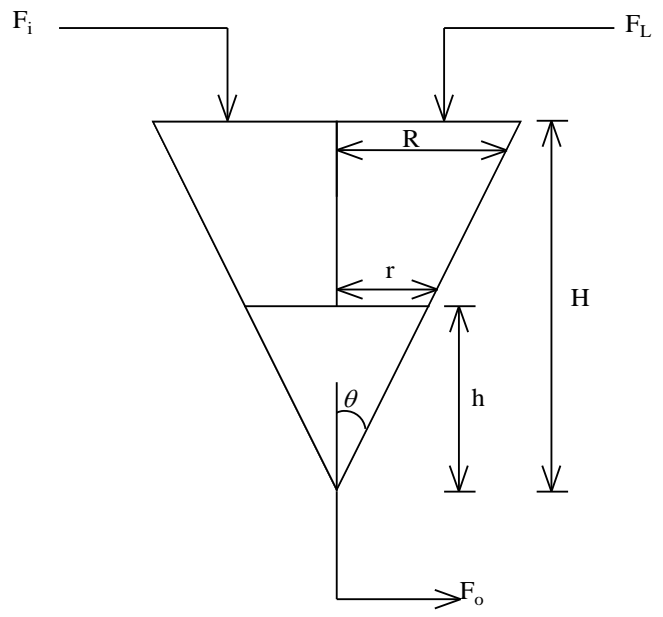

Fig. 2 The conical tank under study

Here $F_{i}$ is the inlet flow rate to the tank, F0 be the outlet flow rate from the tank, $F_{L}$ be the disturbance applied to the tank.

$\mathrm{F}_{\mathrm{i}}=$ Inlet flow rate to the tank $(\mathrm{m} 3 / \mathrm{min})$

$\mathrm{F}_{0}=$ Outlet flow rate from the tank $(\mathrm{m} 3 / \mathrm{min})$

$\mathrm{F}_{\mathrm{L}}=$ Load applied to the tank (1pm)

$\mathrm{H}=$ Height of the conical tank $(\mathrm{m})$

$\mathrm{h}=$ Height of the liquid level in the tank at any time't' $(\mathrm{m})$

$\mathrm{R}=$ Top radius of the conical tank $(\mathrm{m})$

$r=$ Radius of the conical vessel at a particular level of height $\mathrm{h}(\mathrm{m})$

$\mathrm{A}=$ Area of the conical tank $(\mathrm{m} 2)$
First, the plant to be operational, the system parameters are to be taken out. To obtain the system parameters, open loop analysis of the process involved in the study is done. The technique to set the open loop response is process reaction curve method given by Zeigler and Nicholas. Zeigler and Nicholas observed that the open loop response of most control system to a step input change will be an S- shaped curve that can be approximated as first order with dead time system.

Using the data obtained from the open loop response, the FOPDT model for different operating regions is given in the table 1.

Table 1 Transfer Function model of the Conical Tank Level process for various operating region

\begin{tabular}{|c|c|c|}
\hline $\begin{array}{c}\text { Input ADC } \\
\text { Voltage }\end{array}$ & $\begin{array}{c}\text { Level } \\
\text { in cm }\end{array}$ & $\begin{array}{c}\text { Transfer function } \\
\text { Model }\end{array}$ \\
\hline $2.0 \mathrm{v}$ to $2.25 \mathrm{v}$ & $15-30$ & $\frac{5.415 e^{-100 s}}{3000 s+1}$ \\
\hline $2.25 \mathrm{v}$ to $2.5 \mathrm{v}$ & $30-38$ & $\frac{2.999 e^{-350 s}}{3500 s+1}$ \\
\hline
\end{tabular}

The controller parameters tuned using Ziegler Nichols methods are present in the table 2 .

Table 2 Control parameters for PI controller for the models using ZN-PI technique

\begin{tabular}{|c|c|c|}
\hline Parameters & Model 1 & Model 2 \\
\hline $\mathbf{k}_{\mathbf{p}}$ & 4.9861 & 3 \\
\hline $\mathbf{k}_{\mathbf{i}}$ & 0.0149 & 0.00257 \\
\hline
\end{tabular}

\section{DESIGN OF FUZZY CONTROLLER AND FUZZY RULES}

The input to the Fuzzy PI Controller is error and Change-inerror. Fuzzy tuning of PI controller parameters is to find the fuzzy relationship between the parameters of PI controller and error and change in error. Subject to the error at every instant the PI controller parameters $\mathrm{kp}$ and ki are adjusted online thus bringing out the adaptation capability.

The membership function used by fuzzy controller is triangular membership function. The fuzzy subset are Negative Big, Negative Small, Zero, Positive Small, and Positive Big respectively termed as NB, NS, ZO, PS, PB. The performance can be improved by changing the severity of rules. The results of the experiment are used to develop 25rules for the FLC of KP and KI. Tables 3 and 4 present the rule base for the tuning of $\mathrm{Kp}$ and $\mathrm{Ki}$ respectively.

Table 3 Rule Base for tuning Kp

\begin{tabular}{|c|c|c|c|c|c|}
\hline E & NB & NS & ZO & PS & PB \\
\hline NB & PB & PS & PS & PS & ZO \\
\hline NS & PB & PB & PS & ZO & ZO \\
\hline
\end{tabular}




\begin{tabular}{|c|c|c|c|c|c|}
\hline ZO & PS & PS & ZO & NS & NS \\
\hline PS & ZO & ZO & NS & NS & NB \\
\hline PB & ZO & NS & NB & NB & NB \\
\hline
\end{tabular}

Table 4 Rule Base for tuning Ki

\begin{tabular}{|c|c|c|c|c|c|}
\hline $\mathbf{E}$ & NB & NS & ZO & PS & PB \\
\hline NB & PS & PS & ZO & PB & PB \\
\hline NS & NS & NS & NS & NS & PS \\
\hline ZO & NB & NS & NS & PS & PS \\
\hline PS & NS & NS & NS & PS & PS \\
\hline PB & PS & ZO & ZO & PB & PB \\
\hline
\end{tabular}

\section{STRUCTURE OF THE SELF}

\section{TUNNING FUZZY PI CONTROLLER}

The Self tuning fuzzy- PI controller, which takes error "e" and change-in-error "ec" as the input to the controller makes use of the fuzzy control rules to modify PI parameters on-line. The self-tuning of the PI controller refers to finding the fuzzy relationship between the two parameters of PI (i.e.) Kp, and $\mathrm{Ki}$, and the two parameters of fuzzy namely, "e" and "ec".

Fig. 3 displays the block diagram of a fuzzy self-tuning PI controller. As it can be seen from the block diagram, the fuzzification part of the controller takes two inputs (e and ec) and gives two outputs $(\triangle \mathrm{Kp}, \triangle \mathrm{Ki})$ which are fed as the inputs to the PI controller.

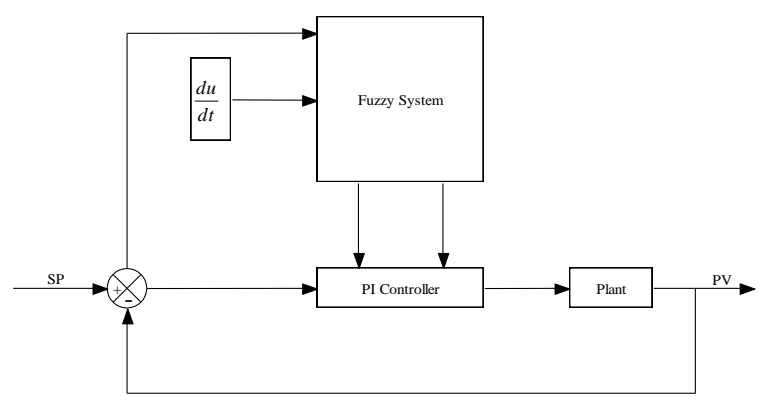

Fig. 3 Structure of self tuning Fuzzy PI Controller

\section{SIMULATION RESULTS}

The modern day processes experience the merits in the use of high level language such as VHDL. The actual implementation of the system follows the specification and reverberate the need for the compliance of speed, power consumption and a sense of reliability. Figs. 4 and 5 exhibit the servo response of the chosen level process for different set points while Figs. 6 and 7 display the regulatory response of the process. The VHDL based Fuzzy PI algorithm based on the parameters tuned using Z-N method is simulated on the Modelsim platform to verify its viability for practical applications.

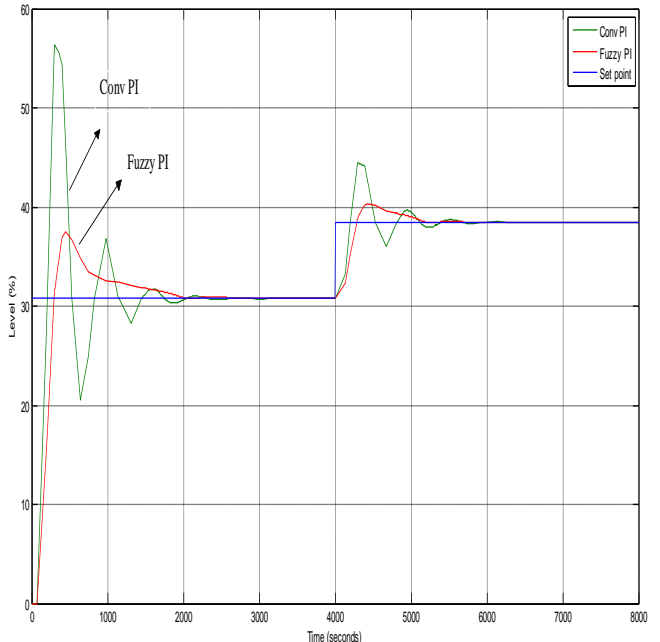

Fig. 4 Servo response of the chosen level process for different set points

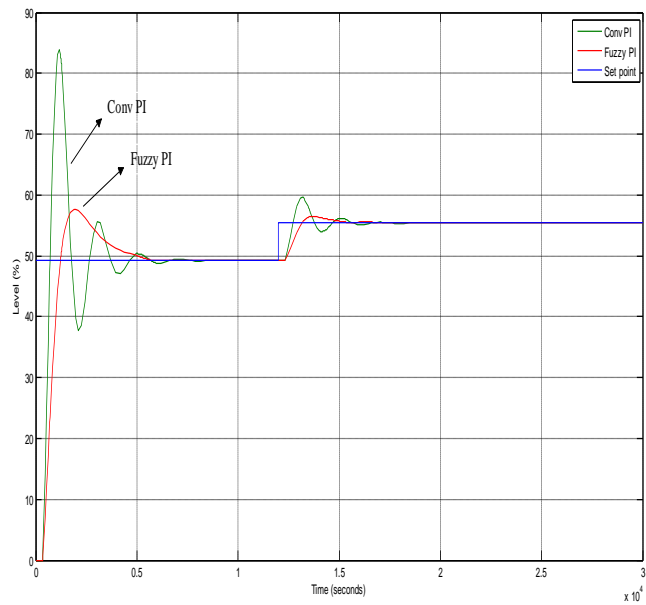

Fig. 5 Servo response of the chosen level process for different set points

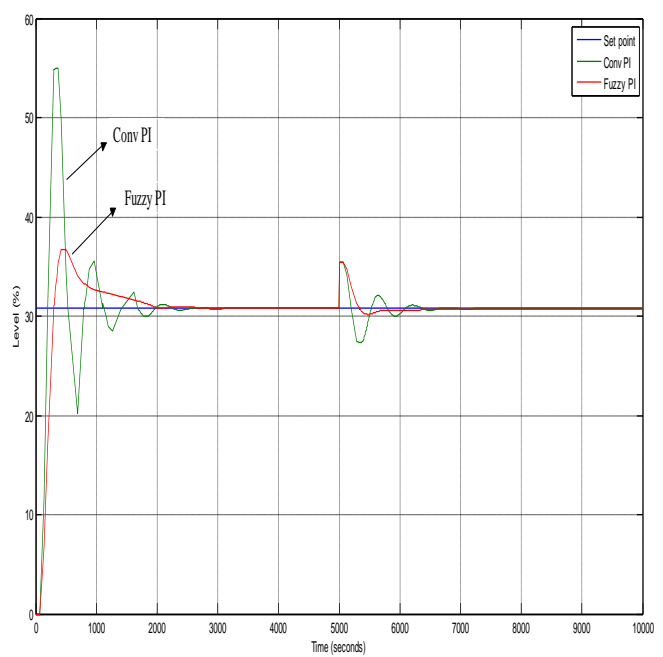

Fig. 6 Regulatory response of the chosen level process 


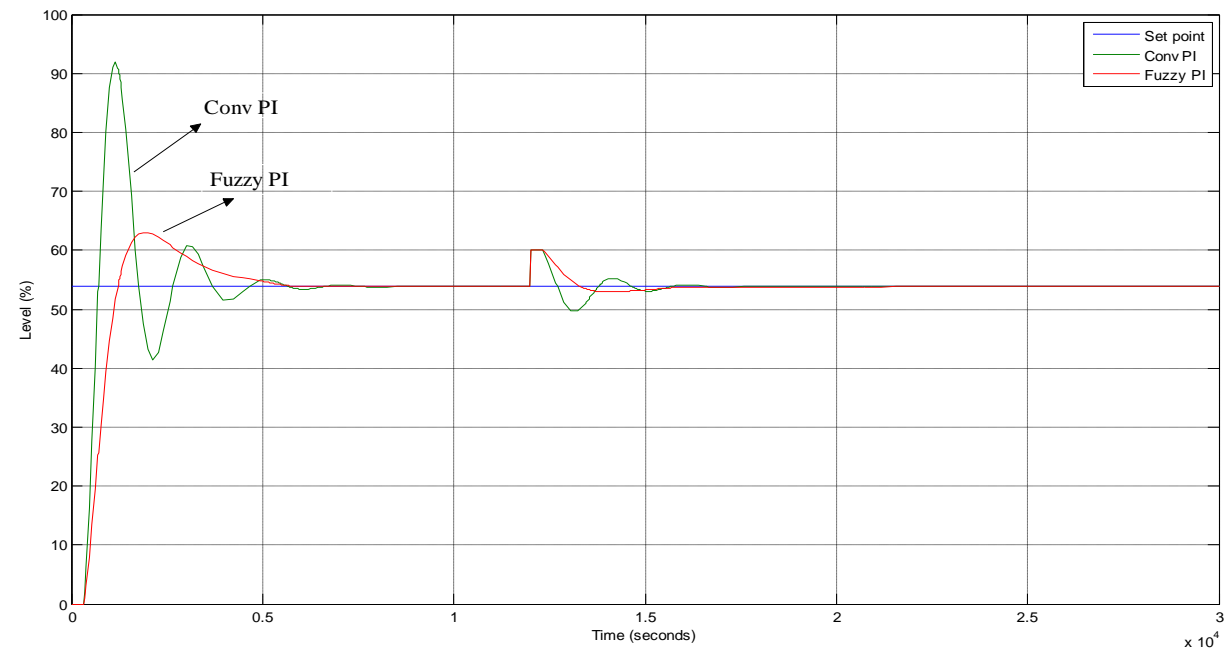

Fig. 7 Regulatory response of the chosen level process

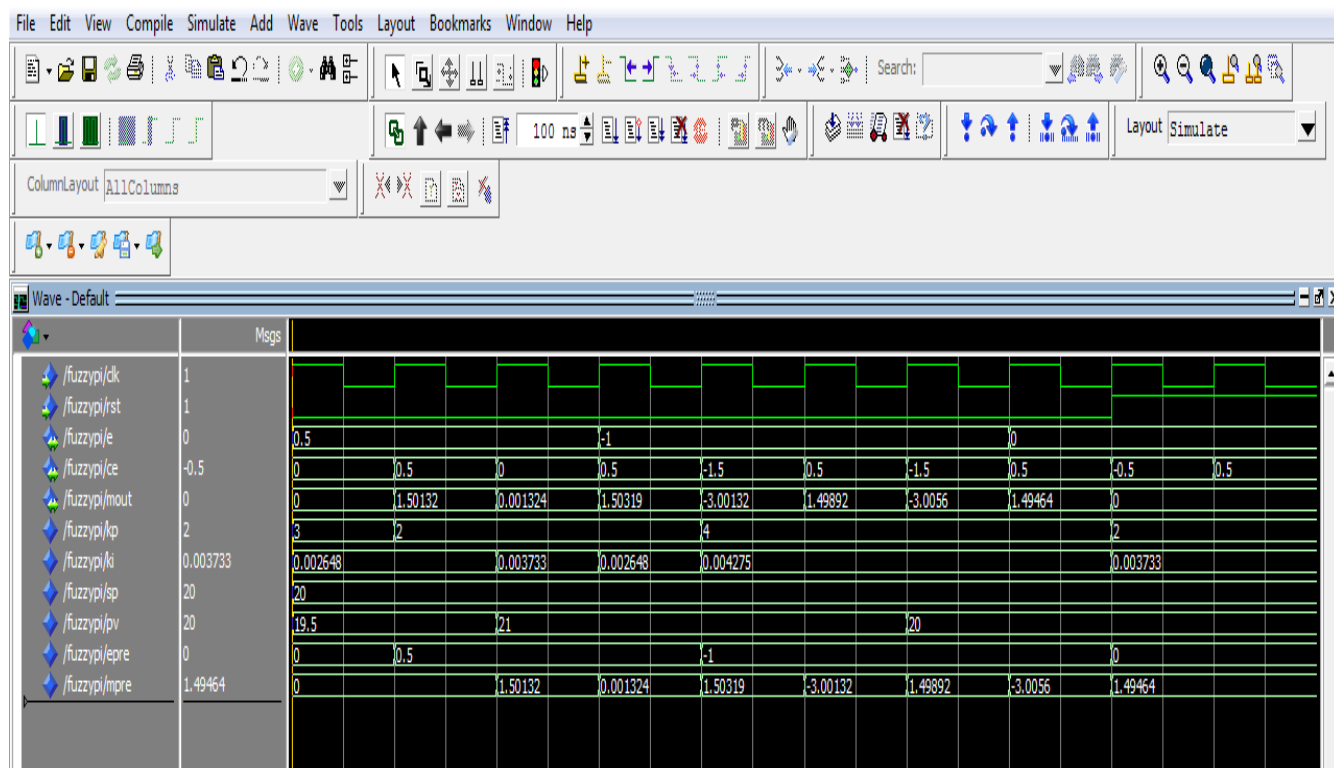

Fig. 8 Output of the fuzzy PI Controller for the set point of $20 \mathrm{~cm}$

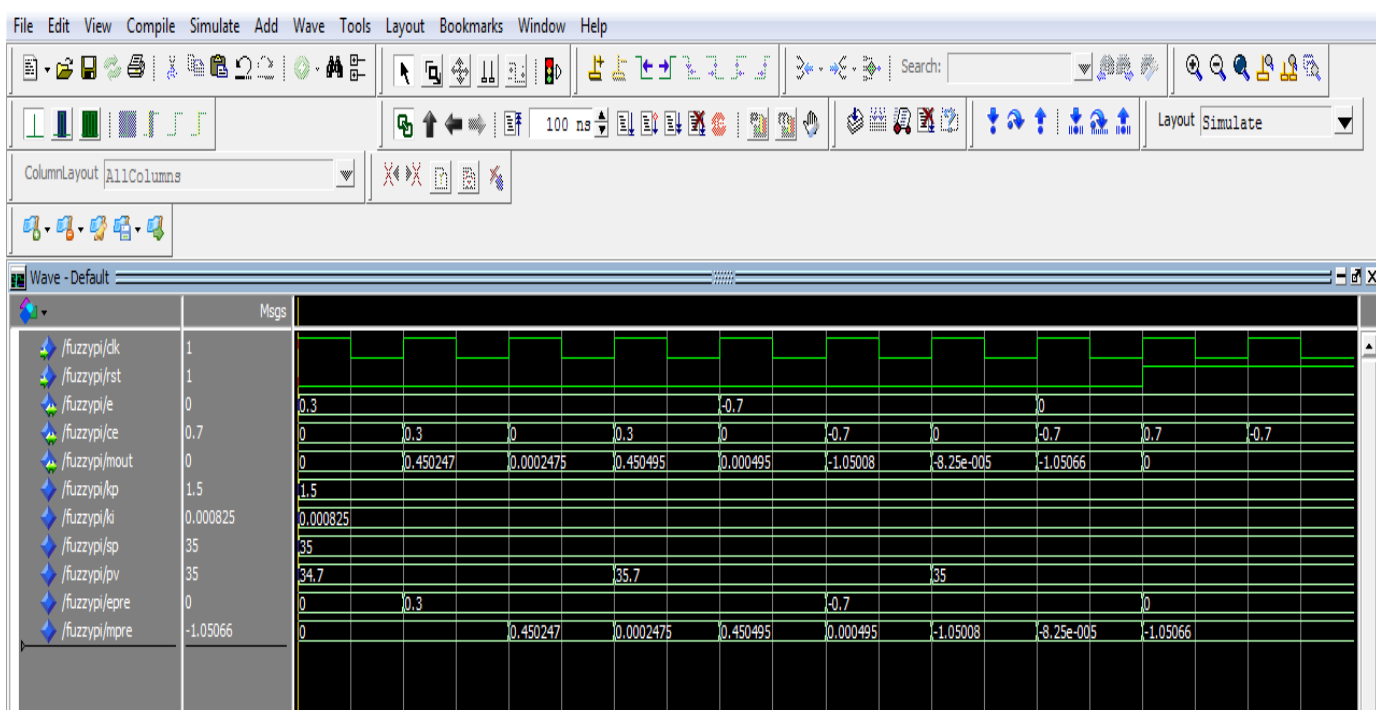

Fig.9 Output of the fuzzy PI Controller for the set point of $35 \mathrm{~cm}$ 


\section{CONCLUSION}

The philosophy involving the features of liquid level process has been articulated. The open loop behavior of the level process involved in the study has been observed on real time and the controller parameters are tuned accordingly. A Fuzzy PI control strategy has been developed with a view to nullify the error and to regulate the level of the liquid in the tank. The obtained closed loop responses for the operating regions taken for analysis are compared with conventional PI controller through Matlab simulation to exhibit the superiority of the proposed control strategy. The Proposed control strategy has been realized using VHDL and the scheme has been evaluated through Modelsim based simulation to verify its suitability for practical applications. To keep in tune with the changing requirements and cater to a large extent of sophistication needed in the modern day process industries, the behavior of the system can be implemented on real time using the state of the art digital device such as Field Programmable Gate Array (FPGA) which can be interfaced with the process to perform the function of the controller and validate the practical applicability of the proposed scheme.

\section{REFERENCES}

[1] Nasri Sulaiman, Zeyad Assi Obaid, M. H. Marhaban and M. N. Hamidon", FPGA-Based Fuzzy Logic: Design and Applications - a Review "IACSIT International Journal of Engineering and Technology Vol.1, No.5, December, 2009 ISSN: 1793-8236.

[2] Md.Shabiul Islam, Nowshad Amin, Mukter Zaman, M.S.Bhuyan,"Fuzzy based PID controller using VHDL for Transportation application", Proceedings of International journal of Mathematical models and methods in applied sciences pp.143-147.

[3] Wen Chen, Hui-mei Yuan, Yan Wang, "Design and Implementation of Digital Fuzzy-PID Controller Based on FPGA", Proceedings of ICIEA 2009 pp.393-397.

[4] George Stephanopoulos, "Chemical Process Control: An Introduction to Theory and Practice", PHI Learning Private Limited, 2010.

[5] B. Wayne Bequette, "Process Control, Modeling Design and Simulation”, Prentice Hall India, 2003.
[6] Douglas L. Perry, "VHDL Programming by Examples", Fourth Edition, Tata McGraw Hill 2003.

[7] Valentina Salapura, Volker Hamann, "Implementing Fuzzy Control Systems Using VHDL and Statecharts", Design Automation Conference, 1996 pp.53-58.

[8] Zeyad Assi Obaid, Nasri Sulaiman, M. N. Hamidon and Mohammed Obaid Ali, "Design Representation of the Multipurpose Fuzzy Logic Controller Using Hardware Description Language", Proceedings of the International Conference on Man-Machine Systems, Malaysia 2009.

[9] Vineet Kumar, B.C.Nakra and A.P.Mittal, "A Review on Classical and Fuzzy PID Controllers", International Journal of Intelligent Control and Systems Vol.16, No.3, September/December 2011 pp. 170-181.

[10] M. Sultan. M. Siddiqui, A. H. Sajid and D. G. Chougule, "FPGA Based Efficient Implementation of PID Control Algorithm", International Conference on Control, Automation, Communication and Energy Conservation, 2009 pp.1-5.

[11] Joao Lima, Ricardo Menotti, Joao M. P. Cardoso, and Eduardo Marques, "A Methodology to Design FPGAbased PID Controllers", Systems, Man and Cybernetics, 2006. SMC'06. IEEE International Conference on (Volume: 3).

[12] Yankai Xu, Kai Shuang, Shan Jiang and Xiaoliang Wu, “ FPGA Implementation of a Best- Precision Fixed - Point Digital PID Controller" 2009 International Conference on Measuring Technology and Mechatronics Automation Record:0 -7695 - 3583 - 8/09.

[13] L.Venkatesan, A.D.Janarthanan, S.Gowrishankar, P.R.Aarthi and G.Saravna Kumar, "Implementation of FPGA Based DA-PID Controller for Temperature System", International Conference on Control Communication \& Computer Technology, 2012, ISBN: 978-93-82208-27-3.

[14] Prof. Vikas Gupta, Dr. Kavita Khare, Dr. R.P.Singh, "Efficient FPGA Design and Implementation of Digital PID Controllers in Simulink", International Journal of Recent Trends in Engineering, Vol.2, No.6, November 2009. 